Cursor_Zeitschrift für explorative Theologie

Discerning Digital Theology

Kyle Schiefelbein-Guerrero

Published on: Nov 06, 2020

DOI: $10.21428 /$ fb61f6aa.cfca0344

License: Creative Commons Attribution 4.0 International License (CC-BY 4.0). 


\section{Discerning Digital Theology}

The first half of 2020 has been marked by quick shifts and societal changes. Very few people could have imagined the differences that just a few months could have on the entire world, affecting racial justice, education, healthcare, the economy, and more. The speed at which these changes have occurred is thanks in large part to the increased presence of interactive technology in the lives of everyday people. The social networking of people without restriction to time and place continues to bring about revolutions.

Particular to this year have been three major transformations, all of which have been connected to the global COVID-19 pandemic. All three of these were quick actions, without much time for preparation, and yet their impact on society were large. The first is the move of worship into the online environment. Having online worship is not new; in fact, I participated in early experiments with the "Church of Fools" website, which began in 2004 and drew upon the interactive Shockwave platform. For some, this website was seen as a novelty, certainly not a replacement for or supplement of the "real" churches that met regularly in-person. Apart from that, many congregations have for a decade been supplementing in-person worship and ministry with video livestreaming. Yet, this year congregations who had no desire to have an online presence were pushed into that environment as governmental officials attempted to prevent the spread of the pandemic.

The second transformation is also not new, but again the rate at which it happened was accelerated by the health crisis. Seminaries and divinity schools, along with higher education in general, have been moving in the direction of online learning for at least two decades, and K-12 schools have been doing so more recently as an option for homeschooling. Yet, some schools have resisted because of the assumption that inperson instruction is more authentic and permits stronger learning. The closure of buildings at all levels across the world forced schools to move quickly online, some having more success than others. Schools are continuing to figure out what their plans are for the fall semester, many with varying levels of online components. Unfortunately, "pandemic pedagogy" is far from good online learning pedagogy, since the former required quick turnaround and focused primarily on content delivery, while the latter attends to interpersonal relationships and knowledge construction. 1 
The third transformation may be the largest of the three, and certainly the one with the loudest impact on society. The evils of systemic racism and white supremacy are not new and in the United States have been woven into the fabric of the nation's origin. The pandemic has made people more aware of the inequities in healthcare and education, and the increased use of recording technology has better documented the injustices that plague humanity. In the age of misinformation and demagogues, there is heightened awareness of authority and how it is abused. Lamentation and protest have spread quickly, both in the online environment and on the streets, demanding changes to racist ideology and institutions. Calls to action appear all over social media, energizing the need "to do justice, and to love kindness, and to walk humbly with your God" (Micah 6:8b NRSV).

These three transformations exemplify the importance of Digital Theology in the 21st century. One may ask how Digital Theology differs from that proffered by existing disciplines. Since the development of personal computers and then the internet, scholars of religion have engaged with digital technology in various ways, from comparing biblical manuscripts to analyzing various nascent rituals in cyberspace. Manuscript examination and data visualization are religious offshoots of the Digital Humanities, which has gained in popularity over the last decade. Other scholars have investigated the sociological aspects of religiosity as it intersects with digital culture, either with emerging online communities or traditional gatherings that have an online extension or presence. This latter work has been the subject of "digital religion" or "religion online."

Theology is a specific discipline, not the same as the sociology of religion, information studies or communication studies. Theology is the critical study of the nature of God, or of God's interaction with the world, or of the world's exploration of the mystery of faith. Theology is about thinking through that connection with the other. As such Digital Theology is distinct from its sister disciplines, which are much more focused on the exploration of the phenomena of religion in digital culture and its meanings.

The articles presented in this issue of Cursor expand on a panel I chaired at the 2019 Annual Meeting of the American Academy of Religion, all attempting to define this emerging discipline. The panel grew out of an article published mid-2019 in the journal Open Theology, positing that Digital Theology can be defined with four levels or waves. $\underline{2}$ 


\section{Levels or Waves of Digital Theology}

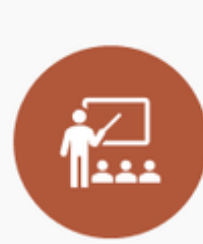

DT1: use of digital technology to communicate or teach theology as a traditional academic subject.

DT3: intentional, sustained and reflexive theologically-resourced engagement with digitality and digital culture.

DT2: theological research enabled by digitality or digital culture.

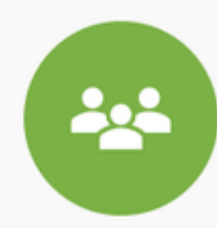

DT4: prophetic re-appraisal of digitality in the light of theological ethics.

The first level of Digital Theology is the use of digital technology to communicate or teach theology as a traditional academic subject, something that many seminaries and divinity schools have been doing for at least a decade. The second is theological research enabled by digitality or digital culture, in which the discipline of theology itself is transformed by cross-disciplinary and interdisciplinary collaboration, and with using digital sources for theological analysis.

The third is intentional, sustained and reflexive theologically-resourced engagement with digitality and digital culture, in which digital culture is the context in which theology is done, altering, adapting and augmenting the traditional theological loci and practices. The fourth is a prophetic re-appraisal of digitality in the light of theological ethics, providing commentary and critique of the ubiquity of technology.

The three transformations mentioned above connect with these various levels of Digital Theology. The increase in online worship opportunities connects with DT3, requiring theological reflection on liturgical theology, sacramental practices and ecclesiology. The move toward more online learning is represented by DT1, where our 
so-called traditional theological subjects are taught in the digital environment. Black Lives Matter and other movements that use digital means to bring about social change links to DT4, especially when concerns about justice both highlight and critique digitality as places of solidarity and division. And of course, this issue of Cursor is a product of DT2 since all the contributors continue to engage in research and writing, even though most of us are in our homes rather than on campus.

So, what does it mean to "discern digital theology," as the title of this introduction suggests? Such a verb not only places this discipline in the realm of theology but also means that it is not static. My own discernment in this discipline can serve as an example. My first exposure to what would become Digital Theology was in overseeing online learning in graduate theological education (DT1). There I was primarily concerned about providing access to teaching and learning in the digital environment. Around the same time, I was engaging with colleagues near and far through digital means, both in my doctoral studies and in research (DT2). Both these levels of Digital Theology were relatively common among my fellow students.

My move to DT3 was the result of blending my employment in online learning with my work in liturgical and theological studies. When I began exploring how to do that, I was introduced to scholars and practitioners working in Digital Theology (some of whom are included in this issue of Cursor) that encouraged my interests and research. As a liturgical scholar I saw the importance of reflecting theologically on online church practices and how these online practices bring about theological adaptation. $\underline{3}$ All digital theologians are called to prophetic discourse, especially as digitality intersects with justice (DT4). Such concerns include lifting up those voices missing from the discipline, especially those from the Global South, as well as critique the lack of access to technology in a society in which it should be ubiquitous.

The articles in this issue are important contributions to this emerging discipline, both in defining/discerning the discipline as a whole and by providing sustained reflection on how theology and digitality intersect and mutually critique each other.

\section{Footnotes}

1. This phrase has appeared in the past couple of months to describe the emergency move to online modalities; see for example Regan A. R. Gurung, "Pandemic Pedagogy: Will Remote Teaching Improve Education?” Psychology Today (April 17, 2020), https://www.psychologytoday.com/us/blog/the-psychologicalpundit/202004/pandemic-pedagogy-will-remote-teaching-improve-education. 
2. Peter Phillips, Kyle Schiefelbein-Guerrero and Jonas Kurlberg, "Defining Digital Theology: Digital Humanities, Digital Religion and the Particular Work of the CODEC Research Centre and Network," Open Theology 5, no. 1 (May 2019): 29-43, https://doi.org/10.1515/opth-2019-0003.

3. My own contribution to this discourse has been "Whether One May Flee from Digital Worship: Reflections on Sacramental Ministry in a Public Health Crisis," Dialog: A Journal of Theology 59, no. 2 (June 2020): 49-55, https://doi.org/10.1111/dial.12549. 